\title{
Performance of E-Health Devices for Frailty Evaluation in Real-Life Settings Is Far from Being Demonstrated
}

\author{
Antoine Piau ${ }^{\mathrm{a}, \mathrm{b}}$ Katherine Wild ${ }^{\mathrm{b}}$ \\ ${ }^{a}$ Gérontopôle, University Hospital of Toulouse, Toulouse, France; ${ }^{b}$ Oregon Health \& Science University, \\ Portland, OR, USA
}

Dear Editor,

Unmet needs are numerous in frailty care and technologies offer new opportunities. Innovations in this field are welcome and the very interesting preliminary work by Zhou et al. [1] ("Instrumented TrailMaking Task: Application of Wearable Sensor to Determine Physical Frailty Phenotypes") raises awareness in an area that should be further developed. As stated by the authors, developing sensitive tools for an in-home assessment and for monitoring changes in frailty is worthy of more research. Recently, the World Health Organization [2] pointed out the importance of tracking walking speed of older adults over time. In-home sensor-based acquisition of physiological parameters is an interesting approach as it could overcome self-report data limitations and allows objective and ecologically valid assessment. However, it is not clear yet, among the multitude of sensors and devices under evaluation, which ones will provide the best evidence for real-life use and what transformation clinicians might expect in their everyday practices.

The iTMT platform addresses the issue of current physical frailty assessment tools, which are alleged to be time-consuming and of limited feasibility. Yet among frailty management, baseline evaluations have been successfully implemented in primary care [3]. Typically, the physical frailty phenotype assessment is only a small part of the evaluation. Thus, the Fried criteria [4] rely on three short questions and two physical tests, namely grip strength and walking speed. Data have consistently indicated that walking speed is one of the strongest parameters to predict adverse outcomes [5, $6]$. We therefore should proceed with caution before proposing alternative tests. Given that this study included eight frail subjects (mean age 77 years), we suggest that it may be premature to propose iTMT as a surrogate marker of frailty.

It is not clear how the iTMT tool presents an advancement in term of time and human resources required, and feasibility from the end users' point of view is not evaluated. While the test took less than 5 min in an optimal setting, a direct comparison with walking speed assessment was not provided. Further, the duration of 1520 min cited for completion of the Fried Frailty Criteria (FFC) [7] is disputable as in the same paper a time range of 5-10 min to perform the FFC is also stated. Moreover, despite self-report limitations, the performances of iTMT could have been compared to other tools as simple as a remote self-administered questionnaire [8]. Reallife in-home application of such technological devices has not yet achieved widespread implementation. None of the cited innovative tools providing metrics irrespective of setting have been evaluated in such conditions.

The frailty prevalence in this sample is consistent with United States estimates in older adults [9]. Nevertheless, when referring to older adults, we usually address a population aged 75 and over, knowing that the mean age of frail older adults is typically greater [3]. In the study by Fried et al. [4] $62 \%$ of frail older adults were 75 years old or older and the prevalence of frailty in the 65- to 70-year-olds dropped down to $3 \%$. Even among this population, most are able to perform a 5-meter walk test. Montero-Odasso et al. [10] showed, among 1,160 very frail older adults $(80+)$, that less than a third presented with severe mobility limitations (e.g., walk up a flight of stairs),

\section{KARGER}

(c) 2019 S. Karger AG, Basel

E-Mail karger@karger.com

www.karger.com/ger
Antoine Piau

Cité de la Santé, University Hospital of Toulouse

24 rue du pont St. Pierre

FR-31059 Toulouse (France)

E-Mail piau.a@chu-toulouse.fr 
which does not imply an inability to walk over a 5-meter path. Indeed, the iTMT study sample does not necessarily fit an old frail population presenting mobility limitations, the reported target of the solution. Subjects were excluded if they were unable to walk $20 \mathrm{~m}$ or had balance impairment limiting their ability to stand for $1 \mathrm{~min}$.

We are currently working on both wearable (e.g., shoe insole, watch) and embedded (PIRs) sensors to accurately assess frail older adults' walking speed in their own environment. In our attempt to address the heterogeneous frail older adult population outside the laboratory environment, we face several barriers in terms of acceptability for monitoring wearable devices and their interfaces (e.g., watch, touch pad). Scientific literature supports this ob-

\section{References}

1 Zhou H, Razjouyan J, Halder D, Naik AD, Kunik ME, Najafi B. Instrumented TrailMaking Task: Application of Wearable Sensor to Determine Physical Frailty Phenotypes. Gerontology. 2018 Oct;25:1-12.

2 Beard JR, Officer A, de Carvalho IA, Sadana $\mathrm{R}$, Pot AM, Michel JP, et al. The World report on ageing and health: a policy framework for healthy ageing. Lancet. 2016 May;387(10033): 2145-54.

3 Tavassoli N, Guyonnet S, Abellan Van Kan G, Sourdet S, Krams T, Soto ME, et al.; Geriatric Frailty Clinic (G.F.C) for Assessment of Frailty and Prevention of Disability Team. Description of 1,108 older patients referred by their physician to the "Geriatric Frailty Clinic (G.F.C) for Assessment of Frailty and Prevention of Disability" at the gerontopole. J Nutr Health Aging. 2014 May;18(5):457-64.

4 Fried LP, Tangen CM, Walston J, Newman $A B$, Hirsch C, Gottdiener J, et al.; Cardiovascular Health Study Collaborative Research servation. In a perioperative e-health intervention, van der Meij et al. [11] proposed a worn activity tracker to 173 young participants (mean age 52 years) with a very low (32\%) compliance rate on the very short term and after an acute event (surgery). Indeed, the longest activity data in real-life setting in a 75+-year-old population are usually collected using embedded sensors, thanks to their unobtrusiveness. Another concern is our future ability to integrate inhome assessment solutions into clinical care. Some expect these technologies to lessen the burden on healthcare professionals. This point is controversial, as the flow of data will converge on already overwhelmed personnel. This could explain, partially, the fact that beyond the use of electronic health records, information and communication technologies have not yet deeply changed our clinical practices. We do not minimize the difficulties of profoundly modifying workflow in existing primary care networks.

The iTMT platform seems to be a promising tool for clinicians. Nevertheless, its usability relies on e-health literacy of an old frail population as compared to the 5-meter walking test, and it warrants further evaluation in a non-optimal setting and population.

\section{Disclosure Statement}

The authors have no conflicts of interest to declare.
Group. Frailty in older adults: evidence for a phenotype. J Gerontol A Biol Sci Med Sci. 2001 Mar;56(3):M146-56.

5 Cesari M, Kritchevsky SB, Penninx BW, Nicklas BJ, Simonsick EM, Newman AB, et al. Prognostic value of usual gait speed in wellfunctioning older people-results from the Health, Aging and Body Composition Study. J Am Geriatr Soc. 2005 Oct;53(10):1675-80.

6 Montero-Odasso M, Schapira M, Soriano ER, Varela M, Kaplan R, Camera LA, et al. Gait velocity as a single predictor of adverse events in healthy seniors aged 75 years and older. J Gerontol A Biol Sci Med Sci. 2005 Oct;60(10): 1304-9.

7 Gary R. Evaluation of frailty in older adults with cardiovascular disease: incorporating physical performance measures. J Cardiovasc Nurs. 2012 Mar-Apr;27(2):120-31.

8 Cesari M, Demougeot L, Boccalon H, Guyonnet S, Abellan Van Kan G, Vellas B, et al. A self-reported screening tool for detecting community-dwelling older persons with frailty syndrome in the absence of mobility disability: the FiND questionnaire. PLoS One. 2014 Jul;9(7):e101745.

9 Bandeen-Roche K, Seplaki CL, Huang J, Buta B, Kalyani RR, Varadhan R, et al. Frailty in Older Adults: A Nationally Representative Profile in the United States. J Gerontol A Biol Sci Med Sci. 2015 Nov;70(11):1427-34.

10 Montero-Odasso M, Bergman H, Béland F, Sourial N, Fletcher JD, Dallaire L. Identifying mobility heterogeneity in very frail older adults. Are frail people all the same? Arch Gerontol Geriatr. 2009 Sep-Oct;49(2):2727.

11 van der Meij E, Anema JR, Leclercq WK, Bongers MY, Consten EC, Schraffordt Koops SE, et al. Personalised perioperative care by e-health after intermediate-grade abdominal surgery: a multicentre, single-blind, randomised, placebo-controlled trial. Lancet. 2018 Jul;392(10141):51-9. 